\title{
Applying ISO 16840-2 Standard to differentiate impact force dissipation characteristics of selection of commercial wheelchair cushions
}

\author{
Martin Ferguson-Pell, PhD; ${ }^{*}$ Grace Ferguson-Pell, BA, BSc, RN; ${ }^{2}$ Farhood Mohammadi, BSc, MSc; ${ }^{3}$ \\ Evan Call, MS $^{4}$ \\ ${ }^{1}$ Faculty of Rehabilitation Medicine, University of Alberta, Edmonton, Alberta, Canada; ${ }^{2}$ College of Nursing (student), \\ New York University, New York, NY; ${ }^{3}$ Faculty of Science, University of Alberta, Edmonton, Alberta, Canada; \\ ${ }^{4}$ Department of Microbiology, Weber State University, Ogden, UT
}

\begin{abstract}
Results from applying the International Organization for Standardization (ISO) 16840-2 test method for determining the impact damping characteristics of 35 wheelchair cushions plus a high resilience (HR70) polyurethane reference foam sample are reported. The generation of impact forces when a wheelchair user either transfers onto a cushion or the wheelchair encounters rough terrain or bumps down a step can endanger the viability of tissues, especially if these forces occur repeatedly. The results demonstrate significant differences in the impact force dissipation characteristics of different cushion products but do not reliably identify differences in performance that can be attributed to descriptive information about cushion composition alone. Instead, these results demonstrate that the materials, proprietary design, and construction features of wheelchair cushions in combination dictate impact force dissipation properties. The results of a cluster analysis are used to generate a model that can be used to compare the impact damping properties obtained from the ISO 16840-2 test method with those of a range of cushions and the reference cushion. Manufacturers will therefore be able to provide users and clinicians with information about the impact force dissipation properties of the cushions that will enable them to make more informed product choices for achieving improved comfort and to protect skin integrity.
\end{abstract}

Key words: anatomical loading, cluster analysis, deep tissue injury, force dissipation, impact damping, pressure ulcer, seating, test method, wavelet analysis, wheelchair cushion selection.

\section{INTRODUCTION}

Wheelchair users frequently engage in activities that involve dynamic loading of the body, generating forces that are transmitted to tissues through the seat surface. Reaching, biomechanics of propulsion, transfers, propulsion on rough terrains, and negotiation of curbs all contribute to the loading history experienced by buttock tissues, with associated potential for discomfort and fatigue and even increased risk for developing deep tissue injury. The impact damping characteristics of wheelchair cushions provide information to assist in the selection of wheelchair cushions to reduce exposure to impact loading and reduce discomfort and risk of injury to wheelchair users.

The International Organization for Standardization (ISO) has published a standard test method for determining the impact damping characteristics of wheelchair

\footnotetext{
Abbreviations: $\mathrm{DI}=$ dissipation index, $\mathrm{FFT}=$ Fast Fourier Transform, IDRCLI = impact damping rigid cushion loading indenter, ILD $=$ indentation load deflection, ISO = International Organization for Standardization, $\mathrm{LCD}=$ loaded contour depth, OD = overload deflection.

*Address all correspondence to Martin Ferguson-Pell, PhD; Faculty of Rehabilitation Medicine, University of Alberta, Edmonton, Canada, T6G 2G4; 780-938-4368.

Email: martin.ferguson-pell@ualberta.ca

http://dx.doi.org/10.1682/JRRD.2014.04.0115
} 
cushions (ISO 16840-2) [1] and employs principles and techniques that have been developed for impact testing of packaging materials [2].

Subsequent to the publication of the test method by ISO and the testing performed in this study, Sprigle et al. suggested refinements to the test method by adding lateral guides to improve repeatability [3]. Sprigle et al. performed additional analysis of the impact response and added three more parameters to describe the impact damping characteristics of wheelchair cushions [3]:

1. Magnitude of the acceleration at initial impact (impact 1).

2. Magnitude of the acceleration at second impact (impact 2).

3. Ratio of impact 2 to impact 1 accelerations.

These three parameters along with other "impact side" analysis and analysis in the frequency domain suggested by Chung [4] are also reported in this article for a wide range of commercial wheelchair cushions.

This study was conducted to assist researchers, clinicians, cushion designers, and wheelchair cushion users wishing to select cushions with preferred impact damping characteristics. Since no benchmark exists for "good" versus "less good" impact force dissipation for wheelchair cushions, a data mining strategy was employed to determine the range of values associated with a relatively large sample (36) of commercially available wheelchair cushions, employing a representative selection of materials and surface shapes in their construction. The relatively simple test, as specified in the ISO 16840-2 procedure, generates an information-rich data set that can be characterized by both amplitude and frequency domain parameters. The data obtained were used to determine which parameter or group of parameters differentiate cushions for their capacity to dissipate impact forces.

From the user's perspective, the reasons why impactdamping characteristics are considered important include-

- The contribution the wheelchair cushion makes to the dynamic seating stability of the user, including "smoothness of ride."

\footnotetext{
* Sprigle, S. Acceleration of the center of gravity of a system during rotation is a function of the distance from the axis of rotation. Internal communication to: ISO Working Group; 2008 Oct and Sprigle, S. Impact dampening results are non-linear and the measured value at the impact side represents the impact dampening characteristics of cushion better than the rebound side of the oscillation. Internal communication to: ISO Working Group; 2008 Oct.
}

- The capacity of the wheelchair cushion to absorb or dissipate impact energy.

- The capacity of the wheelchair cushion to reduce loading conditions that may increase the risk for developing deep tissue injury.

Of course, many other considerations are important in the ultimate selection of the wheelchair cushion, including its effect on posture and other properties that help to reduce the risk of deep tissue injury. ISO 16840-2 provides a battery of tests that provide technical information about a wide range of wheelchair cushion characteristics.

In addition to the parameters specified in ISO 168402, we have added some additional analysis that is intended to provide information that supports the three usercentered requirements listed previously. However, as is the case with other wheelchair cushion properties in the standard, the results in isolation are not intended to directly inform clinical decision-making or user selection. They require information from additional studies that introduce the complexities of individual human body interactions with the cushion and accommodate the wide range of functional tasks that comprise typical use of the cushion in real-world settings. A guide to assist users in making a cushion selection by integration of this information has yet to be developed. However, this article is intended to simplify the way impact force dissipation properties are presented to users, clinicians, and researchers.

\section{METHODS}

\section{Test Method}

The test method employed followed those published in ISO 16840-2 and is illustrated in Figure 1.

The impact damping rigid cushion loading indenter (IDRCLI) was fabricated according to the standard for a $360 \times 500 \mathrm{~mm}$ indenter. A uniformly distributed mass of $51 \mathrm{~kg}$ was achieved by mixing lead shot with epoxy adhesive, placed in a hollow shell formed from a mold fabricated according to the dimensions in the standard. A hinged plywood support was used to position the cushion and the IDRCLI and tilted to $5^{\circ}$ relative to the horizontal prior to release and impact. Hard rubber stops $(25 \mathrm{~mm}$ in diameter) were attached to the under surface of the plywood support as specified in the standard. A Crossbow (San Jose, California) CXL10HF3 3-axis $\pm 10 \mathrm{~g}$ differential accelerometer was used in this study. This accelerometer responds accurately to signals $>0.3 \mathrm{~Hz}$. Pilot studies, 


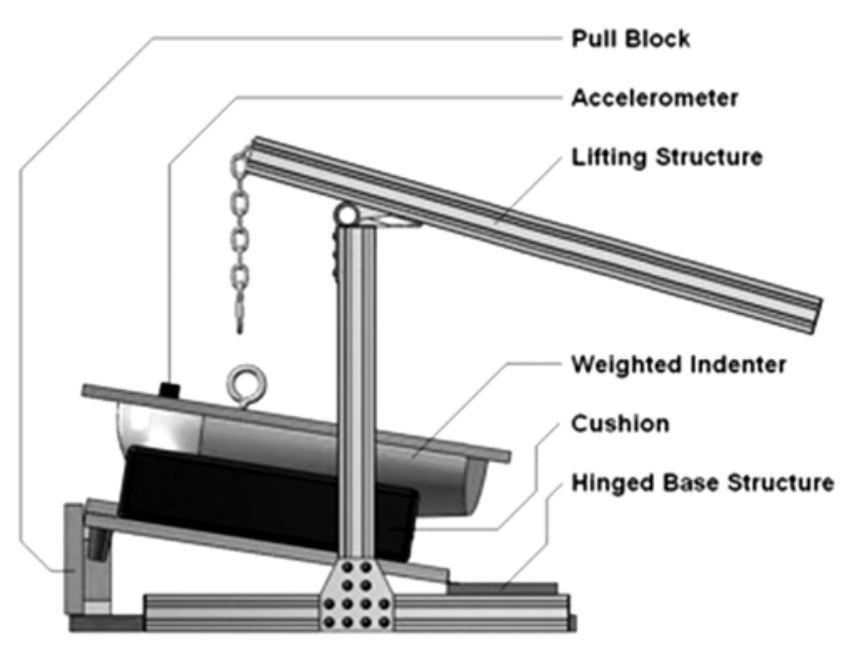

Figure 1.

Impact damping test apparatus.

supported by published data [3], using DC- $500 \mathrm{~Hz}$ accelerometers have shown signals from this test to have a bandwidth in the range of $1-100 \mathrm{~Hz}$. The manufacturer's calibration was used because a simple calibration check using gravity cannot be employed with differential accelerometers. The accelerometer was attached to the IDRCLI on the center line, $127 \mathrm{~mm}$ forward of the rear edge of the IDRCLI. The signal from the accelerometer was connected to a $100 \mathrm{~Hz}$ low pass filter (to prevent aliasing) and was sampled at $1,000 \mathrm{~Hz}$ by a 12 -bit DT302 AD-Converter (Data Translation Inc; Marlboro, Massachusetts) and a custom-programmed Agilent Vee 5.0 (Agilent Technologies; Santa Clara, California) data acquisition program. A $35 \mathrm{~mm}$ wooden block was placed under the front edge of the plywood support to support the $5^{\circ}$ tilt until it was suddenly removed by tugging on a string attached to the block. The acceleration signal from a typical test is shown in Figure 2.

Another test specified in ISO 16840-2 measures the loaded contour depth (LCD) and overloaded contour depth of a wheelchair cushion. These indicate the degree of "envelopment" of the indenter by the cushion. The potential for a relationship between the degree of envelopment and the damping characteristics of the cushion were investigated by measuring these two parameters using the test method specified in the standard.

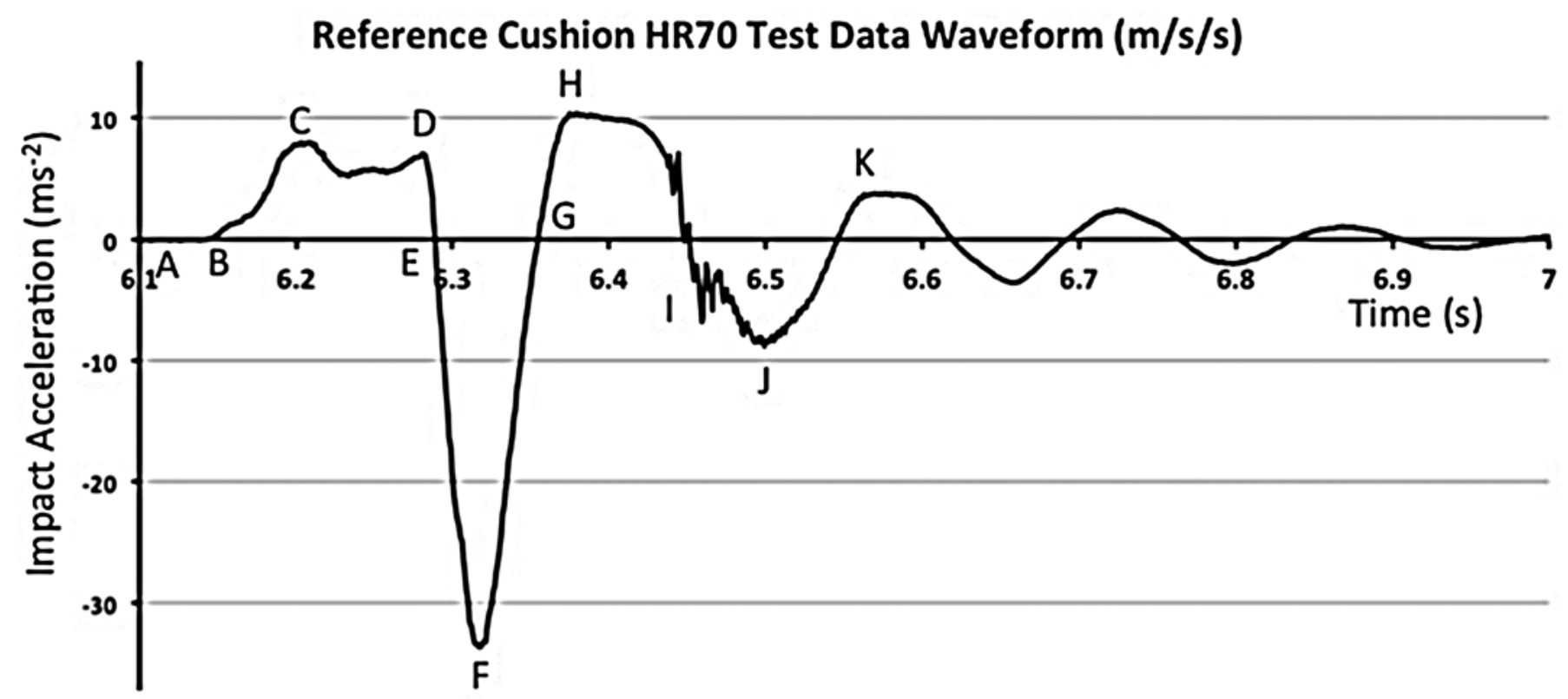

Figure 2.

Typical impact characteristic for HR70 elastic foam. Sampling rate 1,000 Hz. Vertical gridlines = $5 \mathrm{~ms}$. (A) Start of test. (B) Release of block. (C)-(D) Falling. (D)-(F) Impact and first compression. (E)-(G) Zero crossing used to measure $\Delta$ t. (F)-(H) First rebound. (H)-(J) Second compression. (I) Rig "vibration." (J)-(K) Second rebound. Time axis represents elapsed time (in seconds) since start of data acquisition. 
All cushions were equilibrated and preconditioned as specified in the ISO standard. The impact test was repeated six times for each cushion with an interval of $60 \pm 20 \mathrm{~s}$ between each impact. Before these measurements were averaged for each cushion, a post hoc Tukey test was performed to determine whether there was a carryover effect between successive tests. No significant statistical differences were found to indicate carryover effects for any of the variables. The values used in the statistical analysis were therefore the mean for each variable calculated from the six data sets obtained for each cushion. This reduced the variance associated with random experimental error while complying with inferential statistical assumptions for independence of observations.

\section{Sample of Cushions Tested}

The ISO 16840-2 test method was applied to a large sample (36) of representative wheelchair cushions selected for a report on the characteristics of wheelchair cushions for the U.K. National Health Service's Centre for Evidence-Based Procurement. As part of the agreement for conducting this study, and following a consultation process with suppliers, clinicians, and users, wheelchair cushion manufacturers donated typical cushions from their inventory for testing. To ensure a balanced representation of available products, each manufacturer was invited to supply two different wheelchair cushion products through their U.K. distribution network. Their participation, which was facilitated by British Healthcare Trades Association, required that the manufacturer and model of the cushions not be disclosed. In addition, consistent with previous studies [5], a $400 \times$ $400 \times 100 \mathrm{~mm}$ block of high resilience polyurethane foam (HR70) (indentation load deflection [ILD] $=70$, ASTM D5672-9) was tested. This provides a simple benchmark because HR70 polyurethane foam meeting this specification is widely available internationally and is often used as a low-cost simple wheelchair cushion. No cover was used with the HR70 foam sample. No assumptions were made about the effectiveness of the HR70 cushion for impact damping.

\section{Analysis of Impact Data Waveforms}

Figure 2 is an example of a typical data set obtained for a sample of the HR70 reference foam from which the following parameters were determined.

Custom MATLAB (MathWorks, Inc; Natick, Massachusetts) programs were written to calculate the parame- ters reported in this study. The ISO standard calls for the following parameters to be reported from the impact test:

1 . The mean number of rebounds greater than 10 percent of the peak positive acceleration $\left(\mathrm{N}_{>} 10\right.$ percent $)$.

2 . The mean of the first peak rebound, acceleration relative to the baseline $(\mathrm{m} / \mathrm{s} / \mathrm{s})\left(\mathrm{R}_{1}, \mathrm{R}_{2}, \mathrm{R}_{3}\right)$.

3. The mean of the second highest rebound, acceleration relative to the baseline $(\mathrm{m} / \mathrm{s} / \mathrm{s})\left(\mathrm{R}_{2}\right)$.

4. The mean of the ratio of $R_{2}$ to $R_{1}$ as a percentage $\left(\mathrm{R}_{2: 1}\right)$.

Extending these measurements, we also included-

5. The mean of the first three peak impacts, acceleration relative to the baseline $(\mathrm{m} / \mathrm{s} / \mathrm{s})\left(\mathrm{I}_{1}, \mathrm{I}_{2}, \mathrm{I}_{3}\right)$.

6. The mean of the ratio of $I_{1}$ to $I_{2}$ accelerations $\left(I_{2: 1}\right)$.

7. The mean of the third highest peak rebound, acceleration relative to the baseline $(\mathrm{m} / \mathrm{s} / \mathrm{s})\left(\mathrm{R}_{3}\right)$.

8. The duration of the first impact $(\mathrm{s})(\Delta \mathrm{t})$ (see Figure 2).

In addition, following the recommendation of Sprigle et al. [3], the following additional parameters were included in the analysis:

9. LCD (ISO 16840-2) (m).

10. Overload deflection (OD) (ISO 16840) (m).

Building on the recommendations of Chung [4], the frequency composition of the impact pulse was investigated. Fast Fourier Transforms (FFTs) seek harmonic information in stationary signals (continuous harmonic signals, such as oscillations) and might therefore be expected to provide information about the frequency components of multiple rebounds of the indenter following impact. Wavelet analysis, on the other hand, provides amplitude-time-frequency information for nonstationary signals and was used to provide information about the frequencies that comprise a discrete event within the oscillation, such as an impact or single rebound. The data were analyzed using MATLAB routines developed for this study, including the wavelet analysis, and the frequency components of the rebounds were determined using FFT. A sample of the frequency domain results for a typical test is shown in Figure 2. The corresponding parameters recorded were-

11. The mean peak power of the peak frequency generated from the FFT $(\mathrm{m} / \mathrm{s} / \mathrm{s})^{2}\left(\mathrm{FFT}_{\text {power }}\right)$.

12. The mean peak frequency of the frequency spectrum generated from the FFT $(\mathrm{Hz})\left(\mathrm{FFT}_{\text {fre }}\right)$.

Finally two alternative approaches to defining the degree of damping were adopted: 
13. The mean rate of decay of the rebound and impact amplitudes determined by performing a linear regression on the plot of $\log$ (peak rebound and impact amplitude) vs time $\left(\log _{\mathrm{e}}(\mathrm{m} / \mathrm{s} / \mathrm{s}) / \mathrm{s}\right)\left(\mathrm{R}_{\text {Coef }}\right)$.

14. A dissipation index (DI) determined by calculating area under the detrended acceleration vs time trace $((\mathrm{m} / \mathrm{s} / \mathrm{s}) . \mathrm{s})$.

\section{Statistical Analysis of Results for Cushions Tested}

In the absence of a benchmark for an effective impact damping wheelchair cushion, a data mining approach was adopted based on the hypothesis that the cushions tested could be classified into at least two groups of cushions representing good and less good impact damping properties. Two-step cluster analysis was applied to the data using SPSS, version 21.0 (IBM Corporation; Armonk, New York). This clustering test was selected because it is suitable for small data sets, automatically standardizes the data, and automatically determines the maximum number of clusters that can be generated. Loglikelihood was used as the distance criterion, and Akaike Information Criterion was used to automatically determine the maximum number of clusters. The output of the two-step analysis includes a graphical indication of the cohesion and separation of the clusters and a listing of the parameters ranked and scored for their performance in predicting cluster membership.

The data set may be considered to comprise three parameter types. This first is associated with the description of the cushion such as core and cover materials and contour and composite construction. These were not included in the cluster analysis because they were not measurements of the technical performance of the cushion using the ISO test method. Instead, once the clusters had been defined, a cross tabulation was performed to test for a nonparametric association $\left(\chi^{2}, p=0.05\right)$ between these cushion properties and cluster membership (Table 1). A logistic regression was performed to test individually for an association between cushion weight, LCD, and OD with cluster membership. The second parameter type describes the technical performance of the cushion obtained from the ISO impact damping test in the amplitude domain, and the third type describes the frequency domain.

An initial two-step cluster analysis was performed entering all the technical test parameters (amplitude and frequency domains) just defined. The strongest predictors for cluster membership were identified using measures of
Table 1.

Cushion material characteristics and relationship to cluster.

\begin{tabular}{lccc}
\hline \multicolumn{1}{c}{ Property } & $\begin{array}{c}\text { No. of } \\
\text { Cushions } \\
\text { Tested }\end{array}$ & Cluster 1 & Cluster 2 \\
\hline Core Material & 7 & 3 & 4 \\
Air & 8 & 6 & 2 \\
Foam & 7 & 2 & 5 \\
Gel & 14 & 8 & 6 \\
$\quad$ Viscoelastic-Foam & & & \\
Construction & 17 & 10 & 7 \\
$\quad$ Composite & 19 & 9 & 10 \\
Not Composite & & & \\
Shape & 14 & 8 & 6 \\
Contoured & 22 & 11 & 11 \\
$\quad$ Not Contoured & & & \\
Cover & 26 & 13 & 13 \\
Polyurethane & 7 & 6 & 1 \\
Fabric & 2 & 0 & 2 \\
Special & 1 & 0 & 1 \\
$\quad$ None & & & \\
\hline \hline
\end{tabular}

cluster cohesion and separation provided by the two-step cluster analysis. A logistic regression model determined the association between individual test variables' z-score values and the group cluster membership. Outputs of the logistic regression include the percentage of cases correctly classified by that variable alone for group cluster membership. It also provides the $p$-value and $r^{2}$ measure of the goodness of fit of the regression for that variable with the group cluster membership. The results are summarized in Table 2.

To ensure that the results from the model were not "overtrained," a cross-validation was performed by randomly sampling the cushions and repeating the analysis. A 60 percent sample was the minimum size that yielded two clusters. When cushions were ranked by the results from the sampled data model and the whole data set, they were found to be identical and highly correlated using the Spearman rank correlation test.

\section{RESULTS}

\section{Frequency Domain Results}

Figure 3 provides an example of the data obtained from the frequency analysis of a typical set of data obtained from the ISO test method.

Wavelet analysis was not performed routinely for the all the cushions tested. The frequency spectrum within a 
Table 2.

Test parameters that most strongly predict cluster membership listed in order of strongest predictor (using silhouette cohesion and separation coefficient) [Silh Coef]. Using comparison of means, all cluster parameters are individually highly significantly correlated with cluster membership $(p<0.01)$. Potential for using individual parameters to determine group cluster membership was tested using binary logistic regression for z-score of each parameter. Probability, Cox and Snell $r^{2}$, and percentage successfully classified are reported for each parameter.

\begin{tabular}{|c|c|c|c|c|c|c|c|}
\hline \multirow{2}{*}{ Parameter ${ }^{*}$} & \multirow{2}{*}{$\begin{array}{c}\text { Cluster 1 } \\
(n=22), \\
\text { Mean } \pm \text { SD }\end{array}$} & \multirow{2}{*}{$\begin{array}{c}\text { Cluster } 2 \\
(n=14) \\
\text { Mean } \pm \text { SD }\end{array}$} & \multirow{2}{*}{$\begin{array}{l}\text { HR70, } \\
\text { Mean }\end{array}$} & \multirow{2}{*}{$\begin{array}{c}\text { Silh Coef, } \\
\text { Scale (0-1.00) }\end{array}$} & \multicolumn{3}{|c|}{ Logistic Regression } \\
\hline & & & & & $p$-Value & $r^{2}$ & $\%$ \\
\hline Second Impact (m/s/s) I 2 & $6.71 \pm 1.55$ & $12.41 \pm 2.89$ & 8.70 & 1.00 & 0.08 & 0.67 & 94 \\
\hline Third Impact $(\mathrm{m} / \mathrm{s} / \mathrm{s}) \mathrm{I}_{3}$ & $2.41 \pm 0.84$ & $5.52 \pm 1.99$ & 3.47 & 0.82 & 0.01 & 0.59 & 92 \\
\hline Rebound Ratio $\mathrm{R}_{2: 1}$ & $0.41 \pm 0.11$ & $0.64 \pm 0.13$ & 0.40 & 0.65 & 0.003 & 0.46 & 86 \\
\hline Power FFT FFT power & $36.02 \pm 0.14$ & $47.4 \pm 0.38$ & 0.33 & 0.46 & 0.01 & 0.28 & 75 \\
\hline First Impact $I_{1}$ & $0.27 \pm 0.05$ & $0.34 \pm 0.05$ & 0.35 & 0.44 & 0.005 & 0.34 & 72 \\
\hline First Rebound $\mathrm{R}_{1}$ & $9.04 \pm 1.21$ & $10.5 \pm 0.90$ & 10.71 & 0.40 & 0.006 & 0.37 & 78 \\
\hline
\end{tabular}

"See "Methods" section in main text for definitions.

$\mathrm{FFT}=$ Fast Fourier Transformation, $\mathrm{SD}=$ standard deviation

single rebound appears to remain relatively constant, the amplitude gradually attenuating at each rebound.

\section{Influence of Impact Force Dissipation Performance Parameters on Cluster}

The results of the two-step cluster analysis performed on all the ISO test variables automatically identified just two clusters. Table 2 lists the most significant variables in order of predictor importance in the analysis. In this initial cluster analysis, 22 cushions were placed in cluster 1 and 14 in cluster 2. All the variables listed in Table 2 were identified by the two-step analysis as strong contributors to cluster membership as indicated by the silhouette coefficient for cohesion and separation provided by the two-step analysis.

In order to develop a satisfactory statistical model for cluster membership, the cluster parameters must be independent of each other. Not surprisingly, a correlation analysis showed that all the variables identified as strong predictors were also closely correlated (not independent variables) and could not therefore be used to establish a linear logistic regression model.

A binary logistic regression was performed to determine how each individual strong predictor parameter could predict the group cluster membership. This analysis uses the z-score for the parameter and reports the percentage of cases that were successfully classified by the single parameter relative to their group cluster membership. Table 2 shows that second impact and second rebound correctly classified 94 percent of the cushions and also are the strongest contributors to group cluster membership as measured by their silhouette cohesion and separation coefficient. Figure 4 demonstrates the strong differentiation into correct clusters by just using second impact data for each cushion.

A similar analysis was conducted to determine whether clusters could be created specifically in the frequency domain. The peak frequency obtained from the FFT analysis was used to generate the clusters, and twoStep cluster analysis determined there were three clusters that could be differentiated, as shown in Figure 5. The frequency domain analysis was repeated but forced to generate only two clusters to enable a binary logistic regression to be performed. This enabled a comparison between the two sets of clusters (amplitude and frequency) and showed that cushion membership in the two sets of clusters is significantly different between the amplitude and frequency domains.

\section{Relationship Between Cushion Characteristics and Cluster}

The cushion characteristics that were recorded were-

- Mass of the cushion.

- Loaded contour depth and OD.

- Whether or not the cushion was a composite construction.

- Core material used in construction.

- Whether or not the cushion was contoured.

- The material used for the cushion cover. 
(a)

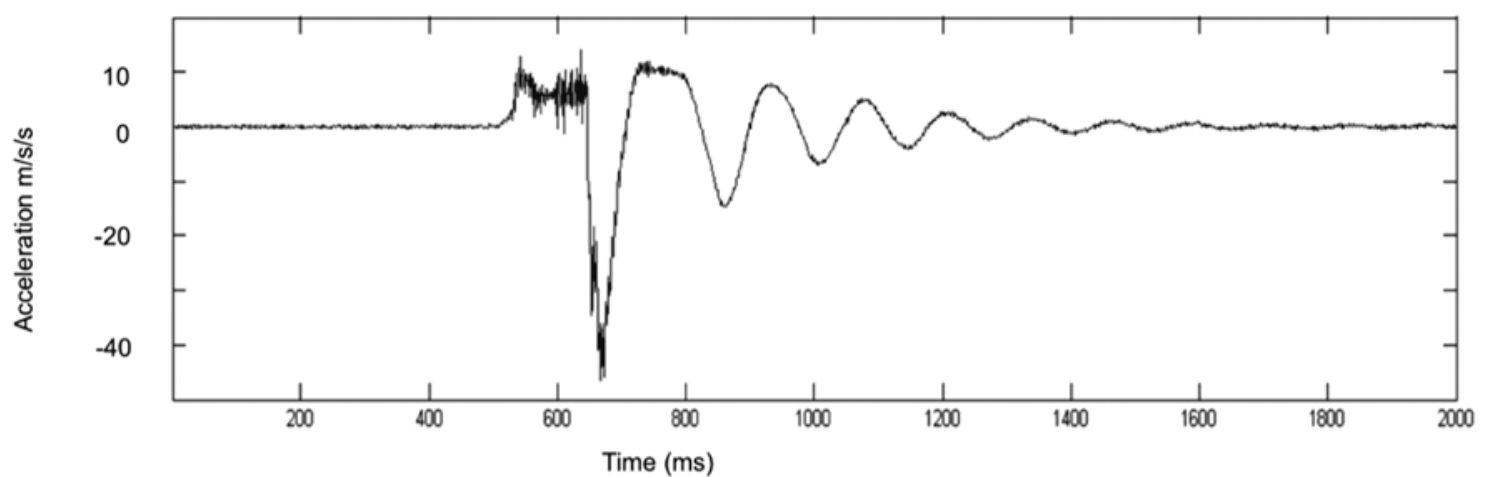

(b)

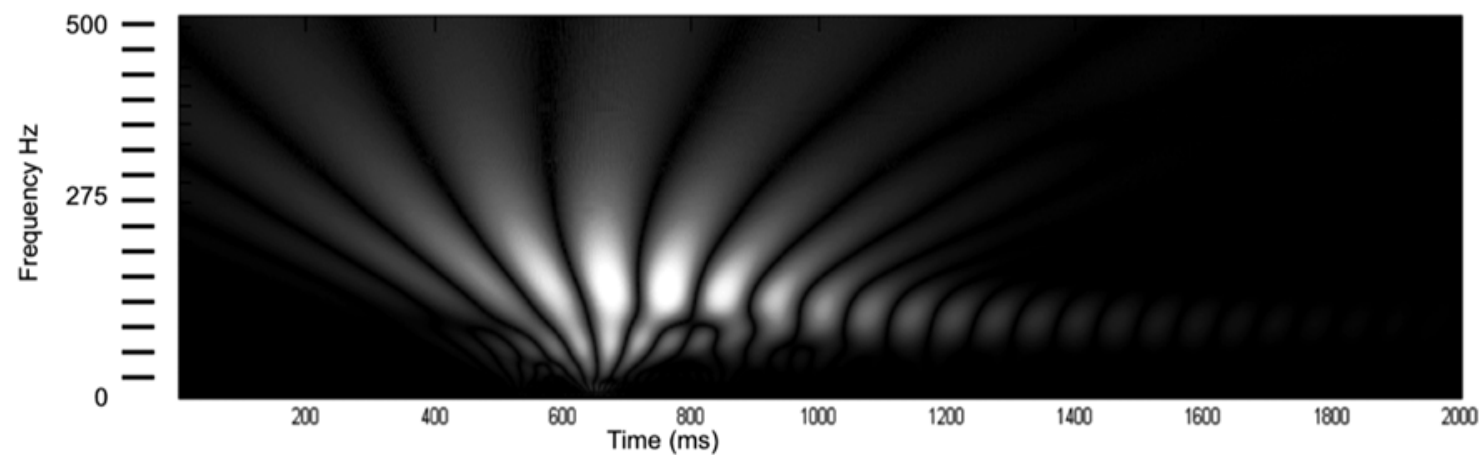

(c)

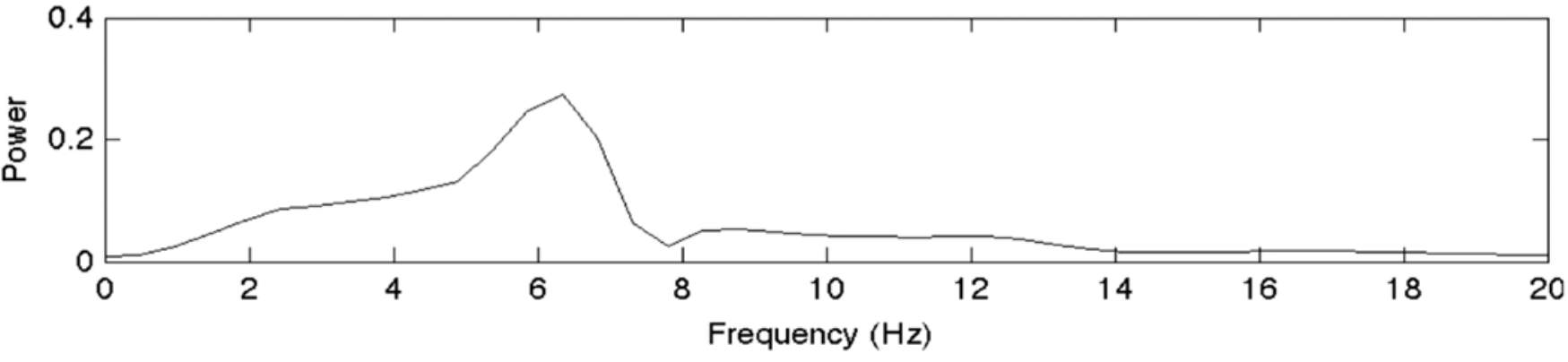

Figure 3.

(a) Typical time vs acceleration plot for International Organization for Standardization impact damping test. High frequency content is attributable to vibrations set up in plywood plate when removing block. (b) Wavelet analysis representing contribution of each wavelet to signal of each impact/rebound cycle (color tone, white representing strongest amplitude contribution). (c) Corresponding Fast Fourier Transform analysis showing most of power in total signal following impact is at $\sim 6 \mathrm{~Hz}$.

The materials used in the fabrication of the cushions were classified into four material classes (air, foam, gel, viscoelastic-foam). Additional subclassifications (such as "solid gel" and "viscous fluid") are desirable but were not adopted in the analysis in order to retain statistical power. Some of the cushions were constructed from several material components and were classified as "composite." The cushions were also classified according to the shape of the top surface "flat" and "contoured." The covering materials used were divided into three groups ("fabric," "polyurethane," "special," "none"). The number of cushions in each category of properties is summarized in Table 1.
The weight of the cushion was weakly correlated with impact ratio, $\mathrm{FFT}_{\text {power }}$ and DI, none of which strongly influence parameter selection in the final model.

\section{DISCUSSION}

The mass of the indenter is constant throughout the experiment. Since the impulse generated by the impact is equal to the change in momentum of the falling test rig, the mass of the cushion could influence the response of the test. The range of cushion weights was $0.3-3.4 \mathrm{~kg}$ 


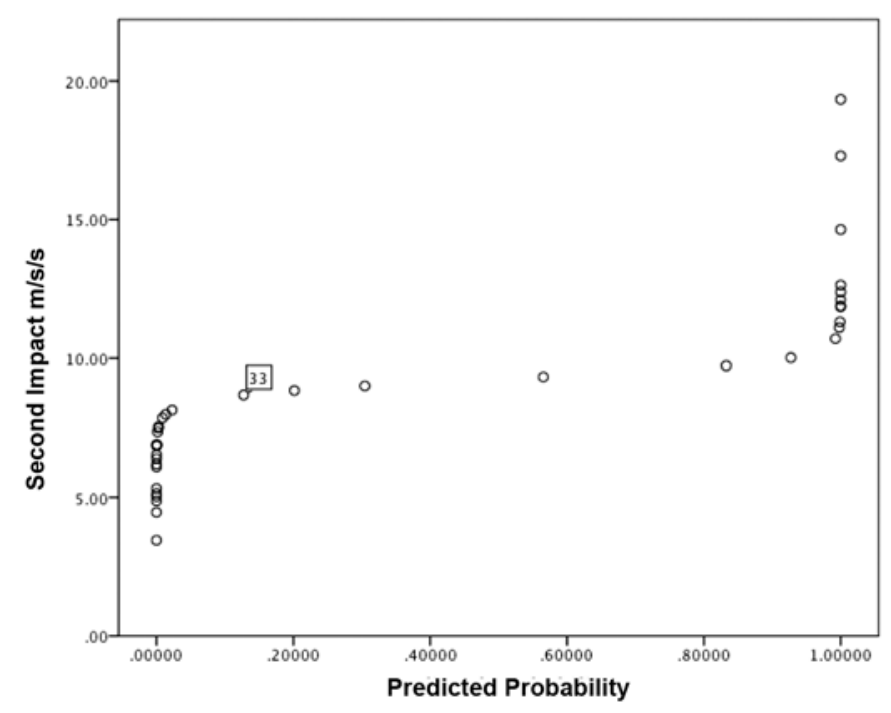

Figure 4.

Probability that second impact measurement for each cushion assigns cushion to cluster 2 . This shows that nearly all cushions are definitely in cluster 2 (predicted probability $\sim 1.0$ ) or definitely not in cluster 2 (predicted probability $\sim 0.0$ ). Reference cushion is identified by its study code $=33$.

adding at most 7 percent to the mass of the $51 \mathrm{~kg}$ indenter. Cushion weight was not found to be statistically correlated with the principal cluster predictors.

The acceleration versus time characteristics of an impact provide direct information about the forces generated during an impact to the cushion and therefore by association to the tissues. The impulse associated with the first impact was substantially larger than subsequent oscillations and was therefore evaluated in closer detail. The ratio of second to first impact $\left(\mathrm{I}_{2}: \mathrm{I}_{1}\right)$ was on average 0.31 (0.09). Although $\mathrm{I}_{2}$ was found to be more consistent in differentiating cushions into clusters (Table 2), it should be noted that $\mathrm{I}_{1}$ represented approximately 70 percent of the dissipated energy and may prove to be of greater clinical significance if impact energy is shown to be directly linked to mechanisms that produce deep tissue injury. Furthermore, the much larger first impact is likely to be associated more strongly with destabilizing sitting posture than subsequent impacts and rebounds.

We found that the mean \pm standard deviation (SD) of composite cushions significantly $(p=0.04)$ resulted in a larger $\Delta \mathrm{t}$ :

- $71.6 \pm 1.19 \mathrm{~ms}$ (noncomposite).
- $74.9 \pm 1.45 \mathrm{~ms}$ (composite).

Contoured cushions had significantly $(p=0.01)$ shorter $\Delta \mathrm{t}$ than noncontoured cushions:

- $70.8 \pm 1.45 \mathrm{~ms}$ (contoured).

- $74.8 \pm 1.19 \mathrm{~ms}$ (noncontoured).

However, $\Delta \mathrm{t}$ had only a marginal effect in determining cluster membership. The mean $\pm \mathrm{SD} \Delta \mathrm{t}$ for all cushions was $73.0 \pm 13.2 \mathrm{~ms}$.

All cushions tested rebounded after impact and exhibited an oscillation that typically decayed in a few seconds. The mean \pm SD frequency of subsequent rebounds for all cushions was $5.6 \pm 0.96 \mathrm{~Hz}$, range 3.9 $7.8 \mathrm{~Hz}$. To achieve a rebound after the impact, the material in the cushion must store some of the energy delivered by the falling indenter and return part of it through elastic recovery. However, each rebound, or "bounce," should be considered to be an additional impact on the tissues. To minimize discomfort associated with an impact event, the ideal cushion would absorb most of the initial impact energy, rather than rely on the tissues to dissipate the impact. Since the ISO test method specified a rigid indenter, the results obtained are specially those dictated by the properties of the cushion. The first impact would ideally have relatively low amplitude and prolonged duration through a combination of material properties (including consideration of nonlinear and viscoelastic properties) and the thickness of the cushion. An ideal cushion would dissipate energy so that multiple impacts do not occur.

The two-step cluster analysis identified second impact and second rebound as the strongest contributors to cluster membership. Further analysis using binary logistic regression also demonstrated that either of these two parameters could be used successfully to accurately (94\%) predict cluster membership. This indicates that in the future only one parameter needs to be disclosed to provide an indication of the impacting force dissipation characteristics of a wheelchair cushion. Small values for second impact and second rebound would suggest the cushion is less likely to wobble during an impact event and destabilize the posture of the user. A large value for second impact/rebound suggests that the cushion has a tendency to store the first impact energy, therefore relying on tissues to dissipate the energy, with increased potential for deep tissue injury. In summary, smaller values of second impact/rebound would seem generally desirable. 


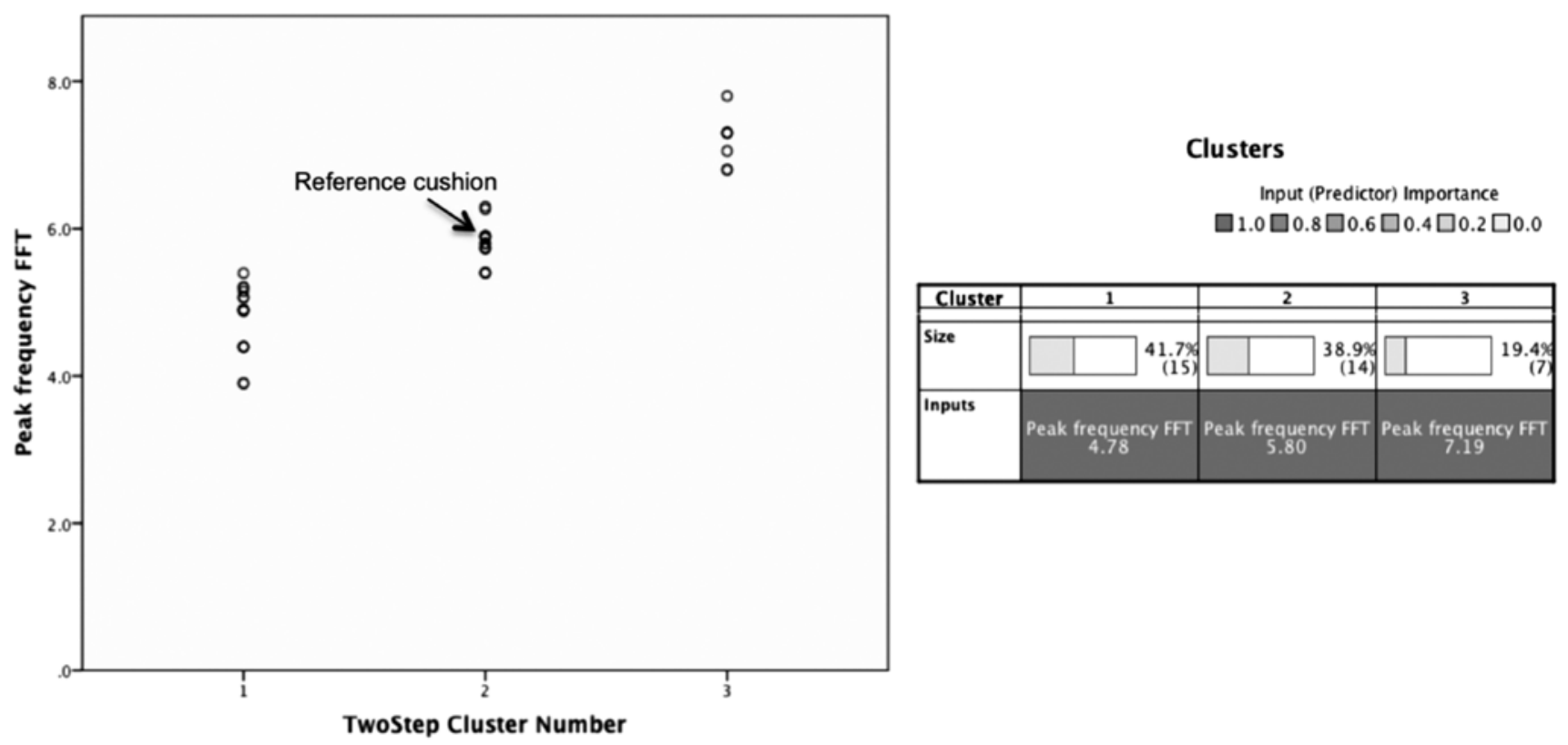

Figure 5.

Analysis similar to Figure 4 indicates successful classification into three clusters when only Fast Fourier Transform (FFT) peak frequency was used to determine cluster membership.

A separate two-step cluster analysis was performed using the peak frequency obtained in the FFT analysis of each cushion. This produced three clusters (mean peak frequencies were: $4.8,5.8$, and $7.2 \mathrm{~Hz}$ ). Comparison with the amplitude domain clusters confirmed that amplitude and frequency domain clusters comprise different cushion memberships. It is unlikely that these differences in rebound frequency have physiological or functional significance to the user.

Wavelet analysis enables us to evaluate the frequency domain in detail during a single impulse. Wavelet analysis confirms the value of the duration of first impact to be about $60 \mathrm{~ms}$, with vibrational frequency components within the impact dominant at about $150 \mathrm{~Hz}$. Although this provides more information than FFT, it is likely that frequency information during the impact may be significantly influenced by the vibrational characteristics of the test rig.

Most of the power in the frequency domain was concentrated around the fundamental frequency of oscillation of the system. The mean \pm SD frequency for all cushions was $5.6 \pm 0.95 \mathrm{~Hz}$. The capacity of a cushion to rapidly dampen impact pulses will reduce the impact energy that would otherwise have to be dissipated in the tissues and skeletal system of the user.

Following the lead of Cochran and Palmieri [5], in Figures $\mathbf{4}$ and $\mathbf{5}$ we identify the value of the relative position in cluster membership for the reference cushion, a high-resilience polyurethane foam, $100 \mathrm{~mm}$ thick, with an ILD of 45:70. In the impact amplitude domain, it is a marginal member of cluster 1 , the group of cushions with lower second impact values, and is in cluster 2 of the frequency domain clusters.

\section{LIMITATIONS OF THIS STUDY}

This study has a number of limitations:

- Only one cushion sample was available for each product tested. The study does not provide information about variations in properties that may occur during manufacture of a particular product. If significant variation does exist within batches of the same product, this could influence the composition of the clusters reported in this study.

- Although the study followed the test procedure specified in ISO 16840-2, there are likely to be differences 
in the impact dissipation characteristics of cushions with temperature, both due to environmental conditions and body heat transferred to the cushion.

- The ISO 16840-2 test only considered impact force dissipation associated with the cushion. The parameters determined in these tests are likely to be significantly affected by soft tissues and the skeletal system displacing during an impact.

- A further limitation of the ISO 16840-2 impact damping test is that it does not provide information about tissue deformation and the potential for deep tissue injury associated with impact loading. This should be a priority for future development of wheelchair cushion performance standards.

- The ISO 16840-2 test is designed to provide information for a "typical" adult. The results of this study are limited in this respect and the clustering outcomes may be significantly different for users of the same cushions whose build is significantly heavier or lighter than the average intended by the specifications of the standard.

\section{CONCLUSIONS}

This study considered an extended set of parameters to characterize the response of a wide selection of wheelchair cushions to the ISO 15840-2 Impacting Damping Under Normal Loading Conditions protocol. Using twostep cluster analysis, nine parameters from the ISO test method were considered to most significantly affect the separation of cushions into two clusters. Of the cushions that were tested, 61 percent were placed in cluster 1 and were noted to have lower impact and rebound force parameters. The remaining 39 percent were placed in cluster 2. A binary logistic regression was performed to determine whether any one parameter could be used to reliably predict membership of the clusters generated by all nine parameters. The second impact and second rebound both assigned 94 percent of the cushions correctly to the clusters defined by the nine parameters, offering a significant simplification when disclosing and interpreting the impact force dissipation characteristics of wheelchair cushions.

A similar analysis was performed in the time domain and three clusters were found to divide cushions according to the peak frequency of oscillation of the indenter after impact. The peak frequency was in the range 3.9-
$7.8 \mathrm{~Hz}$, with means for the three clusters at $4.8,5.8$, and $7.2 \mathrm{~Hz}$. It is unlikely that these relatively subtle differences in rebound frequency are of clinical or functional significance.

These results, and those from other studies that have been performed with a more restricted selection of cushions, indicate that the ISO-16840-2 protocol is generally effective. By measuring the second impact acceleration, it is possible to provide a simple comparison between cushions and also a reference cushion that is widely available. Consideration should also be given to the amplitude of the first impact because this is substantially higher than the second impact and may therefore contribute more strongly to deep tissue injury. Although the ISO standard provides test methods for a range of cushion properties, the integration of the information obtained from each test is left to the user. Hillman et al. have explored, using discriminant analysis, whether the measures in ISO-16840-2 correspond with current subjective clinical knowledge and failed to find a relationship [6]. Further work is needed to establish test methods and models that link technical performance to physiological responses and the preferences of users.

\section{ACKNOWLEDGMENTS}

\section{Author Contributions:}

Study concept and design: M. Ferguson-Pell, E. Call.

Acquisition of data: G. Ferguson-Pell.

Analysis and interpretation of data: M. Ferguson-Pell, E. Call,

G. Ferguson-Pell, F. Mohammadi.

Drafting manuscript: M. Ferguson-Pell.

Critical revision of manuscript for important intellectual content: M. Ferguson-Pell, E. Call.

Statistical analysis: F. Mohammadi, M. Ferguson-Pell.

Obtained funding: M. Ferguson-Pell.

Administrative, technical and material support: M. Ferguson-Pell.

Study supervision: M. Ferguson-Pell.

Financial Disclosures: The authors have declared that no competing interests exist.

Funding/Support: This material was based on work supported in part by peer-reviewed grants from the National Health Service Centre for Evidence-Based Procurement, ASPIRE, Rehabilitation Engineering and Assistive Technology Society of North America, and the National Pressure Ulcer Advisory Panel (United States).

Additional Contributions: This study gained significantly from the contributions and suggestions made by the ISO TC173, SC-1, WG11 Working Group that developed the 16840 family of standards for seating and seat cushions, Chair Geoff Bardsley, PhD. Significant contributions to this article were made by the late Graham Nicholson, PhD, 
and Duncan Bain, $\mathrm{PhD}$, and by Liping Qi, $\mathrm{PhD}$, who undertook the wavelet analysis.

\section{REFERENCES}

1. International Organization for Standardization. ISO 16840-2 Wheelchair seating-Part 2: Determination of physical and mechanical characteristics of devices intended to manage tissue integrity-Seat cushions. Geneva (Switzerland): International Organization for Standardization; 2007.

2. Wang Y, Low KH. Damped response analysis of non-linear cushion systems by a linearization method. Comput Struct. 2005;83:1584-94.

http://dx.doi.org/10.1016/j.compstruc.2005.02.004

3. Sprigle S, Chung B, Meyer T. Assessment of the ISO impact damping test for wheelchair cushions. Assist Technol. 2010;22(4):236-44. [PMID:21306069] http://dx.doi.org/10.1080/10400435.2010.518581

4. Chung B. Dynamic response of wheelchair cushions. Proceedings of the 25th Southern Biomedical Engineering Conference; 2009 May; Miami, FL. New York (NY): Springer; 2009. p. 47-50.

5. Cochran GV, Palmieri V. Development of test methods for evaluation of wheelchair cushions. Bull Prosthet Res. 1980;10(33):9-30. [PMID:7236950]
6. Hillman S, Hollington J, Torres-Sanchez C, Boeckx J, Crossan N. Clinical interpretation of ISO 16840-2 measurements for wheelchair seating cushions. Proceedings of U.K. Posture and Mobility Group (PMG) National Training Event; 2014; University of Warwick, Coventry, United Kingdom.

Submitted for publication April 28, 2014. Accepted in revised form November 10, 2014.

This article and any supplementary material should be cited as follows:

Ferguson-Pell M, Ferguson-Pell G, Mohammadi F, Call E. Applying ISO 16840-2 Standard to differentiate impact force dissipation characteristics of selection of commercial wheelchair cushions. J Rehabil Res Dev. 2015;52(1):41-52.

http://dx.doi.org/10.1682/JRRD.2014.04.0115

ResearcherID/ORCID: Martin Ferguson-Pell, PhD: A2326-2012

\begin{tabular}{|c|c|}
\hline $\begin{array}{l}\text { Au subussions screeneo br: } \\
\text { iThenticate }\end{array}$ & HEHBER \\
\hline 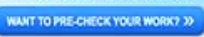 & $\begin{array}{l}\text { CROSSREF.ORG } \\
\text { HHE CITATIOH LINKIHG EACKEOHE }\end{array}$ \\
\hline
\end{tabular}


